\title{
Literatura e indústria cultural: relações com outras produções artísticas, a partir de Gota d'água, de Chico Buarque e Paulo Pontes
}

Agnaldo Rodrigues da Silva

Universidade Estadual do Mato Grosso (Cuiabá, Brasil)

\begin{abstract}
RESUMO: ESTE ARTIGO DISCUTE RELAÇÕES ENTRE A LITERATURA, O TEATRO, A MÚSICA E O CINEMA EM UM CONTEXTO NO QUAL A INDÚSTRIA CULTURAL FORÇA ESSAS PRODUÇÕES A SEREM APENAS PRODUTOS DE CONSUMO. O ESTUDO PARTIU DO TEXTO CÊNICO GOTA D'ÁGUA, DE CHICO BUARQUE E PAULO PONTES, PARA ATINGIR UMA DISCUSSÃO MAIS AMPLA, INDICANDO RUPTURAS E CONTINUIDADES ENTRE AS MANIFESTAÇÕES LITERÁRIAS E ARTÍSTICAS E AS SUAS CONVERGÊNCIAS COM A INDÚSTRIA CULTURAL.
\end{abstract}

ABSTRACT: THIS ARTICLE DISCUSSES RELATIONS BETWEEN LITERATURE, THEATER, MUSIC AND THE CINEMA IN A CONTEXT IN WHICH THE CULTURAL INDUSTRY OBLIGATES THESE PRODUCTIONS TO BE ONLY PRODUCTS OF CONSUMPTIONS. THE STUDY BEGAN WITH THE SCENIC TEXT GOTA D'ÁGUA BY CHICO BUARQUE AND PAULO PONTES, IN ORDER TO ACHIEVE A BROADER DISCUSSION, INDICATING RUPTURES AND CONTINUITIES BETWEEN THE LITERARY AND ARTISTIC MANIFESTATIONS AND THEIR CONVERGENCE WITH THE CULTURAL INDUSTRY.

PALAVRAS-CHAVE: LITERATURA, ARTE, INDÚSTRIA, CULTURA, CONSUMO. KEYWORDS: LITERATURE, ART, INDUSTRY, CULTURE, CONSUMPTION. 
exto cênico que repercutiu como uma provocação em aberto ao sistema de governo vigente, Gota d'água vai ao encontro do que se concebe como literatura de ficção. É, pois, notada a presença da obra na bibliografia dos cursos de Letras, nos ementários das disciplinas de literatura brasileira, de modo que é pelo viés da literatura que há uma maior circulação do livro como produto industrial. Com qualidades literárias atestadas por críticos no quilate de Sábato Magaldi, Adélia Bezerra de Menezes e Gilberto de Carvalho, entre outros, o texto propõe uma reflexão sobre o mundo periférico, com acontecimentos em uma favela do Rio de Janeiro, cujas personagens são lavadeiras, macumbeiros, bêbados e desocupados.

A literatura, com seu caráter ficcional, cuja meta defendida por um grande grupo de pensadores da história e da crítica literária é a humanização do ser, tornou-se, além de várias outras coisas, um mecanismo para se propor meios de transcender a própria existência. Porém, são transcendências possíveis na realidade, uma vez que "se as coisas impossíveis podem ter mais efeito de veracidade que o material bruto da observação ou do testemunho, é porque a personagem é, basicamente, uma composição verbal, uma síntese de palavras, sugerindo certo tipo de realidade" (CANDIDO, 1985, p. 78).

No texto cênico, cuja qualidade literária é um aspecto que o coloca no cânone, essa aproximação entre realidade e ficção articula-se de um modo bem mais consistente do que se observa em um romance, um conto ou uma novela. Leva-se em consideração que esse texto será encenado e que o espectador terá o contato com a trama por meio da representação feita por atores, de modo que analisará os acontecimentos como se estivesse vendo uma realidade, quer dizer, as personagens põem-se vivas no palco, conforme salienta Silva (2008).

Gota d'água é um texto que além de projetar uma denúncia social de fatos corriqueiros em muitas comunidades, traz aspectos políticos subjacentes. A reação contra o sistema socioeconômico e político dialoga com o que Bosi (2002) registrou como sendo literatura de resistência. Assim, como as outras manifestações artísticas da década de 70, os textos cênicos, considerados literatura, estavam impregnados de clichês ideológicos que foram neutralizados pela censura, pois em certo momento da história literária, "o texto passou 
a valer pela sua capacidade de reapresentar os caracteres que se supunham próprios da sociedade que o gerou" (BOSI, 2002, p. 10).

Passou-se, assim, a conceber a literatura como um produto cultural que atinge as massas e é capaz de despertar consciências e, portanto, politizar. Não foi à toa que o texto recuperou o mito Medéia, sob a perspectiva de Eurípides, escritor grego que vivia intensamente os aspectos sociais e políticos de sua época e lugar. Porta voz de uma nova época, Eurípides esforçou-se para servir como poeta a sua pátria, em momentos de crise, conforme afirma Lesky (1998).

Gota d'água apresenta no enredo personagens de vida simples, mas de alta psique, a exemplo das tragédias antigas. Habitantes de um espaço físico degradante, onde não havia luxo, porém, lixo, o texto remete à indústria cultural da música capaz de forjar sentimentos e vontades nada éticos. Desse modo, o sucesso e o dinheiro, adquiridos pela indústria da música, ofereceu ao Jasão a possibilidade de habitar outro mundo que lhe pudesse realizar os sonhos.

A indústria cultural movida pela trama de Gota d'água é reveladora de uma potencialidade que insere a literatura no processo de conscientização da massa. Outrossim, despeja sobre Jasão os efeitos do dinheiro na construção da identidade da personagem. No entanto, o sucesso do protagonista é o resultado do bom comércio da música que fora gravada em disco, o que denota a circulação de capital diante de um produto artístico-cultural. Entra-se em uma discussão crucial: a literatura e a arte vistas como produto de mercado.

A globalização e a evolução das tecnologias de informação e comunicação têm ajudado a formar uma gigantesca indústria cultura sobre a literatura, principalmente a de massa. Diante desse fenômeno, a literatura canônica perde, gradativamente, espaço pela imposição de novos paradigmas e reinvenção de novos estilos. Vive-se em um momento no qual o acesso à literatura e à arte é caro. Em decorrência disso, há uma distorção de metas para comercialização do produto, em que a pirataria tem dominado os espaços de venda. $\mathrm{Na}$ literatura, muitas editoras investem em textos que estão longe do que concebemos como canônico, mas que há grande procura do público leitor. Assim como se tornou fácil e "na moda" publicar um livro sem que a obra tenha realmente um valor estilístico convincente. Mas essa discussão poderia ficar bem mais polêmica se formos considerar as palavras de Todorov, quando afirma: "quem ousaria hoje decidir entre o que é literatura e o que não o é, diante da irredutível variedade 
de escritos que se lhe costuma incorporar, sob perspectivas infinitamente diferentes?" (TODOROV, apud FHILADELFIO, 2003, p. 204).

Diante desse contexto, Chico Buarque e Paulo Pontes propõem como texto cênico uma tragédia moderna brasileira que rompe os estilos até então apresentados pelos dramaturgos nacionais. Há aqueles que dizem que o texto tenha feito sucesso porque Chico Buarque é uma grife da indústria cultural, capaz de promover produtos nos diversos setores da cultura: literatura, música, teatro e a dança (dança incluída nos musicais já produzidos, na encenação de suas peças). Certamente que essas opiniões em nada questionam a qualidade das obras de Chico, mas alertam para o fato de que o nosso cotidiano está construído por uma mega indústria cultural.

Gota d'água, na verdade, mostra-nos uma trama possível de acontecer na realidade, reforçando a tese de que vivemos em uma sociedade que investe na industrialização da literatura e da arte, transformando-as em meios de capital, apesar de que essas potencialidades culturais são as únicas capazes de fazer a diferença no mundo industrializado em que vivemos. Jasão e Creonte, como personagens, são a personificação do capital e da necessidade do dinheiro na vida dos indivíduos. É, pois, preciso ter dinheiro para que sejamos notados, respeitados e valorizados. Esse é um pensamento cruel, porém, é o que move o desfecho de Gota d'água. A vingança da mulher traída fomentada pela sede do homem que a abandonou pelo dinheiro. Alma, personagem pela qual Jasão supostamente abandona Joana, passa a ser um mero pretexto ao desenvolvimento da trama.

Jameson (2001), ao discutir a cultura do dinheiro, enfoca que tudo o que tem sido produzido hoje constitui um fenômeno cultural, em que o produto é comprado pelo marketing que é feito sobre ele ou pela necessidade de seu uso. Desse modo, compra-se não só o que é necessário, mas aquilo que é incentivado a comprar, ou, de outra forma, compra-se pela propagando que é feita do produto. Percebamos, então, que a literatura e a arte são comercializadas, disputando o mercado com outros produtos, e, às vezes, com elas mesmas. As livrarias, por exemplo, hoje disputam as vendas com os sebos, inclusive on line, assim como trava uma histórica luta contra as fotocópias, principalmente entre o público universitário.

Obra que expõe personagens inseridas em um contexto em que a indústria cultural é uma promessa de melhoria de vida, Gota d'água é um texto único e 
literariamente expressivo. A referência à obra de Eurípides e à produção cinematográfica de Oduvaldo são motivos que fizeram desse texto de Chico e Pontes um paradigma na consolidação da tragédia moderna brasileira. Assim, uma Medéia brasileira consegue levar a cabo um tema clássico (a vingança), sob uma perspectiva sociopolítica e econômica corrente de um determinado momento do Brasil. A atitude de Joana, a protagonista, bem poderia ter sido contra o poder que a indústria cultura tem na formação do caráter humano.

\section{II}

Diferente das peças montadas visando a um grande sucesso de bilheteria ou à arrecadação de dinheiro no mundo em que se consolidam, cada vez mais, produções culturais voltadas para a massificação e mercantilização, a peça teatral Gota d'água permaneceu um tempo considerável em cartaz, em 70, voltando à cena por outras vezes não só no Brasil, mas também no exterior. O capitalismo industrial transformou, ao longo do tempo, os bens culturais em produtos de consumo, coisificando a literatura e a arte. Assim, destacam-se livros, jornais, revistas, filmes, pôsteres (books), CDs, entre outros, quer dizer, tudo o que oferece maior circulação do produto pela mídia, seja impressa ou eletrônica.

No entanto, o acesso às variadas formas de cultura, como a literatura, o cinema, as artes plásticas e a música pode ser feito sem a presença dos indivíduos (indivíduos que produziram tais artes ou literatura), facilitando a relação de comercialização. Compra-se, hoje, livros, filmes ou CDs pela internet, ou, simplesmente, podemos ter o acesso gratuitamente, por diversos sites. No caso do filme e da música, criou-se um mercado paralelo, em que há uma invencível produção e comercialização de produtos piratas, combatido duramente pelas políticas de autoria, mas sem muito sucesso. Criou-se, então, a competição entre o original e o pirata, entre os direitos autorais e o barateamento do produto como uma possibilidade de acesso da classe considerada menos privilegiada. Isso não quer dizer que somente essa classe faça o uso desses produtos, uma vez que essa prática atinge uma parte significativa da sociedade.

Contudo, o teatro é uma manifestação cultural que traz um diferencial. Para ter o acesso a ele, é necessária a presença física do indivíduo, na in- 
dispensável relação atores e espectadores (o público), tudo em tempo real. Assim, não há como "piratear" uma representação teatral. Arte, cuja impossibilidade da reprodução mecanizada para o comércio é uma qualidade que a difere das outras, o teatro tem origem na palavra grega theatron, que revela um fundamento essencial: o local de onde o público assiste uma representação que lhe é mostrada em outro lugar. Para Pavis (1999),

...o teatro é mesmo, na verdade, um ponto de vista sobre um acontecimento: um olhar, um ângulo de visão e raios ópticos o constituem. Tão-somente pelo deslocamento da relação entre olhar e objeto olhado é que ocorre a construção onde tem lugar a representação. Durante muito tempo, na língua clássica dos séculos XVII e XVIII, o teatro será também a cena propriamente dita. Por uma segunda translação metonímica, o teatro se torna, enfim, a arte, o gênero dramático (daí as interferências com a literatura, tão amiúdes fatais à arte cênica), mas também a instituição (o Teatro-Francês) e finalmente o repertório e a borá de um autor (o teatro de Shakespeare)... (PAVIS, 1999, p. 372)

O ponto de vista de Pavis leva, gradativamente, à reflexão que ele próprio institui sobre o teatro de massa, cuja relação está intrínseca aos efeitos da indústria cultural. Para ele, a era das artes de massa começou a partir do momento que se passou a ter os recursos técnicos para reproduzir a obra de arte e para atingir o maior número de pessoas pelos meios de comunicação de massa. Ponto de vista que dialoga em muito com as teorias de Benjamin (1985), poderíamos, talvez, dizer que essa manifestação teatral abrange as tendências que conhecemos como teatro popular, de participação ou de massa. Nomenclaturas diferentes, porém, norteadoras de uma técnica de representação teatral que se entrecruzam na prática.

Ao admitir que a peça Gota d'água possa ter característica que a insere no teatro de massa é também lhe atribuir uma localização no teatro político, dado o período em que fora produzida. No entanto, a peça traz como personagens o povo (a massa), mas não necessariamente atingiu o público, como a adaptação que Oduvaldo fez para a TV (o caso verdade). Destaca-se, nesse contexto, a reflexão que Magaldi (2001) fez no seu trabalho Panorama do teatro brasileiro, em que considera a peça de Chico e Pontes uma "excelente adaptação da tragédia Medéia” (MAGALDI, 2001, p.312). Nessa direção, 
...primeiro o cinema e, mais recentemente, a televisão, como em qualquer parte do mundo, pareciam relegar o teatro a função secundária. Alguns programas de tevê são transmitidos hoje, simultaneamente, em várias capitais do país, falando a mais de um milhão de espectadores. A carreira de uma peça, mesmo que se desdobre em todas as cidades, nunca atingirá esse número (MAGALDI, 2001, p. 279).

Dado a conhecer que a peça Gota d'água partiu de um interesse despertado pelo episódio "Medéia", do Caso Verdade, os autores esclareceram, nas partes preliminares da publicação, que a peça foi inspirada em concepção de Oduvaldo Vianna Filho: “dedicamos esta peça à memória de Oduvaldo Vianna Filho" (BUARQUE et PONTES, 1998, p. 7). Nota-se, entretanto, que depois da experiência de Oduvaldo, não houve mais nenhuma adaptação de Medéia para o cinema ou para a televisão brasileira. Do mesmo modo, não houve, ainda, o investimento da indústria cinematográfica ou televisiva em adaptar ou produzir alguma obra baseada em Gota d'água, a exemplo do que fora feito com Ópera do malandro, Benjamin, Estorvo e Budapeste.

No caso de Oduvaldo, temos uma relação entre o teatro e a televisão. No estudo das teorias da representação, vamos perceber que algumas peças de teatro são arquivadas por meio de gravações, ou seja, sob a forma de um vídeo gravado. Pavis (1999) salienta que o teatro representa, na televisão, um papel que não deve ser negligenciado. Porém, a concorrência entre ambos seria desleal, tendo em vista que a televisão multiplica, sem dúvida, dezena de vezes a mais, em uma única noite, o público médio de uma determinada peça. Nesse contexto, resta-nos dizer que a teledramaturgia, ou o próprio cinema, traz nuances e recursos que não estão supostos no teatro, como mediações tecnológicas, simultaneidades, retrospectivas de cenas, montagens e diversas outras etapas até que se chegue à miniaturização para a telinha. Mas façamos justiça ao que afirmam diversos atores: um ator é visto como competente conforme sua atuação no teatro. Tudo isso, é claro, sem fazer juízos de valores.

Quando se fala das continuidades entre teatro e cinema e a relação dessas artes com a indústria cultural, é preciso fazer uma distinção: o acesso ao filme é muito mais barato do que ao teatro, ainda que a televisão, que se põe como meio de comunicação de massa, facilita a interação entre o público e a arte cinematográfica. Assistir a uma peça, hoje, de autores consagrados, encenada por atores famosos pode custar muito dinheiro (sem generalizar); às vezes, 
além do que a maioria da população pode pagar. Isso transforma o teatro em um tipo de produção artística da elite, talvez um descompasso ao que declarara Prado (1993), em Peças, pessoas, personagens, ao analisar Alfredo Mesquita: "o teatro era o sonho que fazia sonhar não só a ele mas toda a sociedade da época” (p. 153-154).

Entre os teóricos, alguns defendem o engajamento da arte, pautados pela possível indissociabilidade do artista dos problemas do seu tempo. Assim, conforme salienta Rosa (2003), Eisler era a favor de um engajamento máximo da arte como função social para a libertação do homem, argumentando que apenas estudar as motivações sociopolíticas que moldam as massas não basta, sendo necessário agir para modificar o mundo. Assim, a arte não era vista apenas como instrumento para conhecimento do mundo, mas, sobretudo, para transformá-lo positivamente. Ao contrário de Adorno (1985), que não comunga com tais ideias, ao passo que para ele deve haver a autonomia da criação artística, de modo que condena a manipulação da arte pela ação política.

Como parte de uma indústria cultural, o teatro e o cinema movem, nos dias de hoje, uma parte significativa do comércio. Desse modo, caso Gota d'água fosse adaptada para o cinema, assim como aconteceu com as outras obras de Chico Buarque, o público teria mais facilidade de acesso à trama. Vale ainda lembrar que o texto foi contemplado com o privilégio significativo da música de mesmo nome. Apesar de mais jovem que o teatro, o cinema conquistou o público da contemporaneidade e se transformou na arte que reúne o maior número de espectadores em todos os cantos do mundo. Também pudera, afinal, o filme é, sobretudo, "uma fotografia, e, como tal, já é uma arte técnica, com origens mecânicas e visando a uma reprodução mecânica, por outras palavras, graças ao baixo custo de sua reprodução, é uma arte popular e fundamentalmente democrática" (HAUSER, 1998, p. 989).

\section{III}

Composição de Chico Buarque, de 1975, a música "Gota d'água" é uma produção que faz parte da trilha sonora da peça, assim como compõe a parte poética do texto. Trata-se, pois, de uma canção que indica uma discussão que permeia a intensa censura do fim do período da ditadura militar. Diferente- 
mente dos livros, os discos, naquele período, eram fortemente censurados, principalmente por envolver uma indústria cultural que movia uma circulação mais intensa do produto.

Mas "com relação à música, ela é muito mais facilmente cortada porque não há o investimento, não há esse respeito ao investimento comercial, como é o caso do cinema" (CARVALHO, 1982, p. 147), afirma Chico Buarque em um de seus depoimentos. Veja-se, que as relações entre literatura, música e cinema estão estabelecidas conforme os investimentos que são feitos e, também, na projeção de circulação desse produto, com vistas ao retorno financeiro, ao passo que os livros são menos vendidos, os discos e os filmes eram mais distribuídos, sendo mais consumidos pela massa.

Com intenso conteúdo político, "Gota d'água” batia de frente com o sistema de governo, um tipo de grito que o povo queria soltar, mas se encontrava reprimido. Nos versos "já lhe dei meu corpo/minha alegria/já estanquei meu sangue/quando fervia", percebemos a presença de uma personagem épica que estaria representando o povo brasileiro (uma Joana, da peça teatral) que clama piedade diante de uma situação insustentável. É, portanto, pela música que Buarque e Pontes constroem o estopim de uma revolta popular que bem podia estar sendo aclamada por eles, indicada pelos versos "olha a voz que me resta/ olha a veia que salta/ pro desfecho da festa/ [...] pode ser a Gota d'água". Assim, tudo o que parece uma canção de amor, transforma-se em um texto de significativa carga ideológica.

No universo das canções de Chico Buarque, não se pode reduzir o conteúdo às meras temáticas. Assim, "Gota d'água” não pode ser meramente considerada uma composição musical de protesto. Deve-se, pois, atentar para uma compreensão maior, em que a arte está envolvida por aspectos de diversas dimensões, como, por exemplo, o cultural, o artístico, o sociológico, o psicológico, o histórico e outros diversos setores da experiência humana. Seria um contrassenso deixar entender que Chico Buarque, intelectual amplamente reconhecido e notável artista da contemporaneidade, pudesse deixar a sua obra desprovida de aspectos que a tornasse fundamentalmente humanística. Nessa direção, Silva afirma que se deve

...combater as interpretações que, de uma forma generalizada, prendiam a poesia de Chico Buarque ao contexto circunstancial da Canção de Protesto, ad- 
vertindo que enquadrá-la a uma circunstância efêmera, qualquer que fosse sua natureza, seria negar-lhe a validade poética e reduzi-la a coisa nenhuma (apud, FERNANDES, 2004, p. 173-174).

Poetizando a voz dos excluídos, a letra da música tornou-se o discurso da protagonista da peça, Joana. Um ponto de partida para que houvesse a abertura ao povo brasileiro que, sumido das produções culturais das décadas de 60 e 70, voltasse à cena em produções artísticas nas quais ele próprio seria o protagonista. Não podemos negar que falar do povo e para o povo pode abrir um leque maior de possibilidades para identificação do indivíduo para com o produto. Ao identificar-se com a letra de uma música, por exemplo, poderia haver um consumo mais frenético do disco, CD ou DVD, movendo, a contento, a indústria cultural do setor.

Não estamos mais na era dos discos de vinil. Os CDs e os DVDs têm tomado conta do mercado que dá acessibilidade à produção musical, atravessado por um mercado paralelo que se criou via internet e produtos piratas. Hoje, para ter acesso à música (letra e canção), basta acessar um site e a partir dele gravar no próprio computador, pen drive, CD ou DVD tudo o que quiser ouvir. Porém, a música não perdeu o seu poder de aguçar a sensibilidade humana e de atirar o indivíduo ao êxtase da autorreflexão (quiçá reflexão existencial). Enfim, a música que se faz atemporal é aquela que apresenta, sobremaneira, um resumo geral da vontade do mundo, cujos princípios artísticos e humanos "tem o poder de transformar aqueles pensamentos enojados sobre o horror e o absurdo da existência em representações com as quais é possível viver" (NIETZSCHE, 1992, p. 56).

\section{Referências bibliográficas}

ADORNO, Theodor et HORKHIEMER, Max. Dialética do esclarecimento. Rio de Janeiro: Zahar, 1985.

BENJAMIN, Walter. Magia e técnica, arte e política: ensaios sobre a literatura e história da cultura. São Paulo: Brasiliense, 1985.

BOSI, Alfredo. Literatura e resistência. São Paulo: Companhia das Letras, 2002.

BUARQUE, Chico et PONTES, Paulo. Gota d'água. Rio de Janeiro: Civilização Brasileira, 1998. 
CANDIDO, Antonio. A personagem de ficção. São Paulo: Perspectiva, 1985.

CARVALHO, Gilberto. Chico Buarque: análise poético-musical. Rio de Janeiro: Codecri, 1982.

EURÍPIDES. Medéia. Tradução de Millôr Fernandes. Rio de Janeiro: Civilização Brasileira, 2004.

FHILADELFIO, Joana Alves. Literatura, cultura e formação humana. Caderno de Pesquisa, s/1, 120, p. 203-219, fev 2003.

HAUSER, Arnold. História social da arte e da literatura. São Paulo: Martins Fontes, 1998.

JAMESON, Fredric. A cultura do dinheiro: ensaios sobre a globalização. Petrópolis: Vozes, 2001.

LESKY, Albin. A tragédia grega. 3a . ed. São Paulo: Perspectiva, 1998.

MAGALDI, Sábato. Panorama do teatro brasileiro. 5a. ed. São Paulo: Global, 2001.

NIETZSCHE, Friedrich. O nascimento da tragédia. São Paulo: Companhia das Letras, 1992.

PAVIS, Patrice. Dicionário de teatro. São Paulo: Perspectiva, 1999.

PRADO, Décio de Almeida. Peças, pessoas e personagens. São Paulo: Companhia das Letras, 1993.

ROSA, Ronel Alberti da. Música e mitologia do cinema: na trilha de Adorno e Eisler. Rio Grande do Sul: Unijuí, 2003.

SILVA, Agnaldo Rodrigues. Projeção de mitos e construção bistórica no teatro trágico. Campinas: RG, 2008.

SILVA, Anazildo Vasconcelos. O protesto na canção de Chico Buarque. In FERNANDES, Rinaldo (Org.). Chico Buarque do Brasil. Rio de Janeiro: Garamond, 2004, p. 173-179.

Recebido em 04 de maio e aprovado em 08 de junho de 2011. 